\title{
Intrathecal Buprenorphine Induced Severe Respiratory Depression
}

\author{
Balasubramanya $\mathrm{H}^{1}$, Parimala ${ }^{2}$ \\ ${ }^{I}$ (Associate Professor, Department of Anaesthesiology, VIMS, Bellary, India.) \\ ${ }_{2}^{2}$ (Assistant Professor, Department of Anaesthesiology, VIMS, Bellary, India.)
}

\begin{abstract}
A 38 yearold female patient underwent abdominal hysterectomy under spinal anaesthesia. Thirty micrograms of buprenorphine was added as an adjuvant to intrathecalbupivacaine. Near the completion of the surgery patient developed severe respiratory depression which was initially managed with administration of oxygen along with awakening of the patient at regular intervals for about 15 minutes. Since the patient was deeply sedated and $A B G$ analysis showed severe respiratory acidosis, patient was intubated and mechanically ventilated. Intravenousinj.naloxone (total $0.8 \mathrm{mg}$ ) could not reverse the respiratory depression. Patient's respiratory depression was spontaneously reversed 8 hours of mechanical ventilation. This case report highlights the possibility of occurrence of severe respiratory depression following intrathecal buprenorphine.
\end{abstract}

Keywords:buprenorphine, intrathecal,naloxone, respiratory depression, spinal anaesthesia

\section{Introduction}

Buprenorphine is a long acting, mixed agonist-antagonist opioid anaelgesic. It is highly lipophilic and has high affinity for mu receptors.Buprenorphine has been widely used intrathecally as an adjuvant to local anaestheticsfor many years, because of its easy availability, economy and long duration of action combined with minimal side effects[1]. It has been used intrathecallynot only for postoperative anaelgesia, but also for intractable pain and phantom pain conditions, in the doses of $30-60$ microgram $(\mathrm{mcg})$.

It was found to be safe even in elderly patients[2].Although the respiratory depression to intrathecal opioids is well established, it is not been reported to intrathecal buprenorphine (ITB) till now.

\section{Case Report}

A 38 year old, $50 \mathrm{~kg}$ female patient with pelvic inflammatory disease was posted for total abdominal hysterectomy. Patient was moderately built and moderately nourished. Patient's history, systemic examinations and routine laboratory investigations were unremarkable. After connecting routine pre-induction monitors and preloading with $800 \mathrm{ml}$ of RL, spinal anaesthesia was given using $25 \mathrm{G}$, Quincke needle, $2.8 \mathrm{ml}$ of bupivacaine (heavy) with $30 \mathrm{mcg}$ of buprenorphine in left lateral position. A sensory block up to T6 dermatome was obtained.Surgery was started with Pfannenstiel incision. Patient complained of pruritus around the nose after 8 minutes. At $16^{\text {th }}$ minutepatient vomited twice. There were two episodes of hypotension which was successfully managed with inj. mephentermine $3 \mathrm{mg}$ given intravenously (iv). At $45^{\text {th }}$ minute of intrathecal injection, her $\mathrm{O}_{2}$ saturation $\left(\mathrm{SpO}_{2}\right)$ started falling. There was sinus tachycardia, but her blood pressure was stable.Patient was found to be drowsy but responded to verbal commands.Her respiratory rate was 8 to 10 / min and her chest expansion appeared to be adequate.Oxygen supplementation was given through Hudson mask and patient was awakened at regular intervals, encouraged to breathe. With these measures her $\mathrm{SpO}_{2}$ was maintained above $95 \%$ for another 15 minutes.Intraoperative bleeding was negligible.

At the end of surgerywhich lasted for an hour,patient was haemodynamically stable but she was very drowsy respondingonly to painful stimuli and repeatedly had bradypnoea. It was not possible to maintain $\mathrm{SpO}_{2}$ Her pupils were miotic and sluggishly reacted to light. Arterialblood gas analysis(ABG)showed $\mathrm{pH}$ of 7.12, $\mathrm{PaCO} 2$ of $92 \mathrm{~mm} \mathrm{Hg}, \mathrm{HCO} 326.8 \mathrm{mmol} / \mathrm{L}, \mathrm{PaO} 2$ of $62 \mathrm{~mm} \mathrm{Hg}$ and $\mathrm{SaO} 2$ of $85 \%$.Patient was intubatedafter giving inj.propofol $50 \mathrm{mg}$ iv and mechanical ventilation was instituted with SIMV mode. Inj.naloxone $0.4 \mathrm{mg}$ iv was administered slowly but her condition did not improve. One more dose was repeatedafter 3 minutes without any benefit.Propofolivinfusion was started at $50 \mathrm{mcg} / \mathrm{kg} / \mathrm{min}$, titrated to improve the acceptability of endotracheal tube. Meanwhile her blood sample was sent for random blood sugar, serum electrolytes, serum calcium and free T3,T4 and TSH levels and were later found to be within normal limits.

After 6 hours patient's conscious levels and spontaneous efforts gradually started improving.Patient was put on CPAP mode. When her ABGparameters were returned to near normal values with minimal support,propofolivinfusion was stopped and patientwas extubated. Rest of the course in hospital was uneventful. 


\section{Discussion}

There are no clear-cut definition of respiratory depression in the literature. Several definitions were used. Among them respiratory rate less than 8-10 per minute, $\mathrm{SpO}_{2}$ less than $90 \%, \mathrm{PaCO}_{2}$ more than $50 \mathrm{~mm}$ $\mathrm{Hg}$,need for therapeutic intervention such as administration of naloxone were popular [3]. Levels of sedation and $\mathrm{ABG}$ are more reliable signs of respiratory depression, whereas respiratory rate and $\mathrm{SpO}_{2}$ are unreliable and may delay executing definitive measures[4].

Although buprenorphine has a high affinity for various opioid receptors, its effect at the mu receptor is most important for respiratory depression. Administration of lipophilic opioids may be associated with significant, early respiratory depression $[4,5]$.

Risk factors for respiratory depression with neuraxial opioids include increasing dose, increasing age, concomitant use of systemic opioids or sedatives, possibly prolonged or extensive surgery, the presence of comorbid conditions, and thoracic surgery $[4,5]$.But in our case patient had no risk factors.

There are contradicting reports of reversal of ivor epidural buprenorphine induced respiratory depression by naloxone. Early clinical studies indicated buprenorphine induced respiratory depression following iv or epidural was resistant to naloxone[3].In a study on human volunteers, neither the level of sedation nor respiratory depression induced by iv buprenorphine $0.3 \mathrm{mg}$ was consistently reversed by naloxone, even with doses as high as $10 \mathrm{mg}$ [3].Duration of action of buprenorphine is considerably longer( $>6 \mathrm{hrs})$ than that of naloxone $(30-60 \mathrm{~min})$. High affinity of buprenorphinefor opioid receptors with relatively short duration of action of naloxone were consideredas causes for non-reversal [3].

Van Dorp Eet al studied the effect of various doses of naloxone in reversing ivbuprenorphine induced respiratory depressionand found bell shaped reversal curve with maximal reversal at doses in between $2-4$ mg.A continuous infusion $(4 \mathrm{mg} / \mathrm{hr})$ following the bolus doseprovided full, sustained reversal within $40-60$ minutes of both 0.2 and $0.4 \mathrm{mg}$ iv buprenorphine-induced respiratory depression [6]. They postulated that bellshaped reversal curve may be related to the existence of two mu-opioid receptor subtypes, one mediating the agonist effects of opioids at low dose and the other mediating antagonistic effects at higher dose[7].

We were hesitant to give further dose of naloxone as dose of ITB given was minimal and optimal dose of naloxone required to reverse effects of ITB is yet to be ascertained.The possibility of significant haemodynamic alterations such as tachycardia, hypertension, cardiac arrhythmias, pulmonary oedema, and even cardiac arrest when higher doses of naloxone is used for reversal was our additional concern[3,5]. Probably lower dose of naloxone used in our case may be the cause for non-reversal of respiratory depression induced by ITB. Titrated dose of naloxone combined with haemodynamic monitoring could reverse the ITB induced respiratory depression.

Non opioid respiratory stimulants such as doxapram and almitrine could have been useful in our case. But they were not available in ourhospital that point of time. Their side effect profiles and toxicities limit their wide spread use [8].

\section{Conclusion}

Buprenorphine can cause early respiratory depression following intrathecal administration.Levels of sedation and arterial blood gas analysis are more reliable than respiratory rate and pulse oximetry in diagnosing respiratory depression. Reversal of respiratory depression may be possible but requires higher initial dose of naloxone followed by continuous infusion. There is a need for continuous respiratory monitoring when buprenorphine is administeredintrathecally.

\section{References}

[1]. Nalini V, Roberta LH.Buprenorphine pharmacology and clinical applications, Seminars in anaesthesia, Perioperative medicine and Pain2004; 23,281-290.

[2]. Capogna G, Celleno D, Tagariello V, Loffreda-Mancinelli C. Intrathecal buprenorphine for postoperative analgesia in the elderly patient. Anaesthesia,1988;43 (2),128-30.

[3]. Dahan A, Aarts L, Smith TW.Incidence, Reversal, and Prevention of Opioid-induced Respiratory Depression, Anesthesiology2010; $112,226-38$

[4]. Andrew Hindle MB, Intrathecal opioids in the management of acute postoperative pain. Continuing Education in Anaesthesia. Critical Care \&Pain2008;8,81-85.

[5]. Robert WH, Christopher LW. Acute post-operative pain, in: Ronald D. Miller editor, Miller's anaesthesia. $7^{\text {th }}$ ed(Philadelphia:Churchill Livingstone Elsevier; 2010) p.2769.

[6]. Van Dorp E, Yassen A, Sarton E, Romberg R, Olofsen E, Teppema L, et al.Naloxone reversal of buprenorphine-induced respiratory depression, Anesthesiology2006;105,51-7.

[7]. Sarton E, Teppema L, Dahan A.Naloxone reversal of opioid-induced respiratory depression with special emphasis on the partial agonist/antagonist buprenorphine.AdvExp Med Biol 2008;605,486-91.

[8]. Golder FJ, Hewitt MM, McLeod JF.Respiratory stimulant drugs in the post-operative setting, RespirPhysiol Neurobiol,2013; 189(2),395-402. 